\title{
NO synthesis, unlike respiration, influences intracellular oxygen tension.
}

JEROME COSTE ${ }^{\#}$, JEAN-CLAUDE VIAL $^{*}$, GILLES FAURY ${ }^{\#}$ ALAIN DERONZIER ${ }^{+}$, YVES USSON $^{\circledR}$, MICHEL ROBERT-NICOUD ${ }^{\text {\& }}$ and JEAN VERDETTI ${ }^{\#}$

\# Groupe d'Electrophysiologie Moléculaire, ${ }^{+}$LEOPR-UMR CNRS 5630, ${ }^{*}$ LSP-UMR CNRS 5588, Université J. Fourier, BP 53X, 38041 Grenoble, FRANCE.

${ }^{{ }^{\circledR}}$ Laboratoire TIMC-UMR CNRS 5525, ${ }^{\&}$ Laboratoire DYOGEN-INSERM U309, Institut Albert Bonniot, Université J. Fourier. Domaine de la Merci, 38706 La Tronche cedex, FRANCE.

Corresponding author:

Jean Verdetti

Groupe d'Electrophysiologie Moléculaire, Université J. Fourier, BP 53X, 38041 Grenoble, FRANCE.

Tel: (33)476635820

Fax: (33)476514218

Email: Jean.Verdetti@ujf-grenoble.fr 


\begin{abstract}
We have developed a new phosphorescent probe, PdTCPPNa ${ }_{4}$, whose luminescence properties are affected by local variations of intracellular oxygen tension $\left(\mathrm{PO}_{2}\right)$. Spectrofluorimetric measurements on living human umbilical venous endothelial cells loaded with this molecule show that a decrease in extracellular oxygen tension induces a fall of $\mathrm{PO}_{2}$, illustrating the phenomenon of oxygen diffusion and validating the use of this probe in living cells. Moreover, $\mathrm{KCN}$ - or 2.4-dinitrophenol-induced modifications of respiration do not lead to detectable $\mathrm{PO}_{2}$ variations, probably because $\mathrm{O}_{2}$ diffusion is sufficient to allow oxygen supply. On the contrary, activation by acetylcholine of endothelial nitric oxide synthase (eNOS), that produces NO while consuming oxygen, induces a significant decrease in $\mathrm{PO}_{2}$ whose amplitude is dependent on the acetylcholine dose, i.e. the eNOS activity level. Hence, activated cytosolic enzymes could consume high levels of oxygen which cannot be supplied by diffusion, leading to $\mathrm{PO}_{2}$ decrease. Other cell physiology mechanisms leading to $\mathrm{PO}_{2}$ variations can now be studied in living cells with this probe.
\end{abstract}

Key-words: endothelium, intracellular oxygen tension, porphyrin, fluorescence 


\section{INTRODUCTION}

In the cellular respiratory function, part of the energetic metabolism is accompanied by an oxygen intake and a $\mathrm{CO}_{2}$ discharge in the environment (1). In addition, non-mitochondrial enzymes, not involved in the respiratory function, can also use oxygen: nitric oxide synthase (NOS) is a cytoplasmic enzyme which produces a vasomodulator and neuromodulator gas, nitric oxide (NO), from the precursor L-Arginine, while consuming oxygen (2). In animal cells, extracellular oxygen influx occurs by diffusion through the cell membrane and the intracellular medium, according to the gradient of concentration existing because $\mathrm{O}_{2}$ is consumed into cells. Using data from the literature $(3,4)$, the maximum oxygen flow entering a cell (diameter: $10 \mu \mathrm{m})$ by simple diffusion can be calculated in the range of $3 \times 10^{-15} \mathrm{~mol} \mathrm{O}_{2} \cdot \mathrm{sec}^{-1} \cdot \mathrm{cell}^{-1}$.

In biological tissues, various means can be used to measure oxygen, such as spectrophotometry (5), oxygen microelectrodes $(6,7)$ and oxygraphy, the latter technique having allowed calculation of basal respiratory $\mathrm{O}_{2}$ consumption in human umbilical vein endothelial cells (HUVEC): $4 \times 10^{-17} \mathrm{~mol}$ $\mathrm{O}_{2} \cdot \sec ^{-1} \cdot \operatorname{cell}^{-1}(8)$. Also, non-invasive molecular probes, whose luminescence properties are affected by oxygen, have also been developed to study intracellular $\left(\mathrm{PO}_{2}\right)$ or extracellular oxygen tension. For instance, the phosphorescent albumin-bound-Pd meso-tetra (4-carboxyphenyl) porphyrin, has been intravenously injected for in vivo tissue $\mathrm{PO}_{2}$ measurements in Hamster Skinfold (9) and in rat skeletal muscle (10). Recently, other investigators have measured intracellular $\mathrm{PO}_{2}$ modifications in response to variations of extracellular $\mathrm{PO}_{2}$ in isolated dead muscle skeletal fibers (poisoned with $2 \mathrm{mM} \mathrm{NaCN}$ ) from Xenopus laevis by microinjection of albumin-bound Pd meso-tetra (4-carboxyphenyl) porphyrin (11).

In the present work, we have improved the solubility of the phosphorescent oxygen probe Pd-meso-tetra (4-carboxyphenyl) porphyrin (12) by using a chemically-prepared and purified tetra sodium salt derivative $\left(\mathrm{PdTCPPNa}_{4}\right)$. In contrast to the porphyrin microinjection technique used by Lo et al. in their studies on poisoned cells (12), our probe presents the capability of being loaded non-invasively in living cells. On living human umbilical venous endothelial cells (HUVEC), we have studied the relative impacts on $\mathrm{PO}_{2}$ of two physiological intracellular mechanisms consuming $\mathrm{O}_{2}$, i. e. mitochondrial respiration and extramitochondrial NO synthesis, together with the effect of hypoxia on 
the intracellular $\mathrm{PO}_{2}$, induced by a decrease of the extracellular $\mathrm{PO}_{2}$.

The spectrofluorimetry measurements indicate that both extracellular $\mathrm{PO}_{2}$ decrease and endogenous endothelial nitric oxide synthase (eNOS) activation induce a transient decrease in intracellular $\mathrm{PO}_{2}$, whereas modulation of the mitochondrial respiration does not result in a significant variation of $\mathrm{PO}_{2}$. These findings lead to the hypothesis that maximal $\mathrm{O}_{2}$ diffusion across the cell membrane is sufficient for continuous oxygen supply in mitochondrial respiration, whereas $\mathrm{O}_{2}$ diffusion is insufficient to continuously provide with $\mathrm{O}_{2}$ the activated cytoplasmic enzymes, such as eNOS, that consume high levels of $\mathrm{O}_{2}$. 


\section{MATERIALS AND METHODS}

\section{Pd-meso-tetra (4-carboxyphenyl)porphyrin tetra sodium salt derivative.}

0.185g of Pd-meso-tetra (4-carboxyphenyl)porphyrin (Porphyrin Products) was neutralized by addition of $13 \mathrm{ml} \mathrm{NaOH}(0.065 \mathrm{~N})$. The resulting red solution was stirred for 2 hours at room temperature and filtered, before being evaporated near to dryness $(\approx 0.5 \mathrm{ml})$. The precipitate, Pd-meso-tetra (4-carboxyphenyl)porphyrin tetra sodium salt (PdTCPPNa $\mathrm{Pa}_{4}$, was filtered off, washed with ethanol and dried under vacuum. Yield: $90 \%, 169 \mathrm{mg}$.

Intrinsic luminescent properties of the initial molecular phosphorescent probe are not affected by this treatment: emission spectra of PdTCPPNa ${ }_{4}$ in water solution, obtained with a $514 \mathrm{~nm}$ laser beam, also shows a maximum emission peak at 710nm (Fig. 1A).

Similar to previously published investigations $(13,14)$, the $\mathrm{O}_{2}$-dependence of the probe phosphorescence is described by the Sterm-Volmer relationship: $\tau_{0} / \tau=1+\mathrm{k}_{\mathrm{q}} \tau_{0} \mathrm{PO}_{2}$ where $\tau_{0}$ and $\tau$ are the phosphorescence lifetimes (decay) in the absence of $\mathrm{O}_{2}$ and at a given $\mathrm{PO}_{2}$, respectively, and $\mathrm{k}_{\mathrm{q}}$ (the quenching constant) is a second order rate constant that is related to the frequency of collisions between $\mathrm{O}_{2}$ and the excited triplet state of PdTCPPNa 4 . An intracellular oxygen tension $\left(\mathrm{PO}_{2}\right)$ decrease in the environment increases the phosphorescence intensity (I) and lengthens the phosphorescence decay $(\tau)$ of PdTCPPNa 4 , and inversely. Here, I and $\tau$ were followed, as markers of the $\mathrm{PO}_{2}$ variations, in acellular solutions or in $\mathrm{PdTCPPNa}_{4}$-loaded endothelial cells.

\section{Human Umbilical Venous Endothelial Cells (HUVEC).}

HUVEC were used for several reasons. The endothelial cells have a glycolytic potential enabling them to stand hypoxia or short duration anoxia (15). Also, endothelial cells allow the investigation of three different mechanisms for inducing potential changes in $\mathrm{PO}_{2}: \mathrm{i}$ ) decrease in extracellular oxygen (by argon bubbling), ii) use of uncouplers and inhibitors of the mitochondrial respiration, and iii) stimulation or blockade of eNOS.

HUVEC were obtained according to a protocole derived from the Jaffe's method and, for investigations of $\mathrm{PO}_{2}$ by fluorescence confocal microscopy, HUVEC were cultured on dishes whose bottom was a glass slide coated with $0.25 \mathrm{mg} \cdot \mathrm{ml}^{-1}$ fibronectin $(16,17)$. 


\section{Determination of optimal active concentrations of KCN and DNP using oxygraphy technique.}

Respiration rate of HUVEC suspended in PSS $\left(2 \mathrm{ml}, 5 \times 10^{6}\right.$ cells. $\left.\mathrm{mL}^{-1}\right)$ was measured polarographically in a stirred oxygraph vessel $\left(37^{\circ} \mathrm{C}\right)$ including a Clark oxygen electrode. Different concentrations of the respiration inhibitor potassium cyanide $(\mathrm{KCN})$ or of the uncoupler of mitochondrial phosphorylative oxidation 2.4-dinitrophenol (DNP) were then added and the effect on cellular $\mathrm{O}_{2}$ consumption was recorded.

\section{Control of probe penetration in the cells.}

Fluorescence images of adherent HUVEC were acquired by using a Zeiss LSM 410 confocal laser scanning microscope (Zeiss). Excitation: $514 \mathrm{~nm}$, dichroic $560 \mathrm{~nm}$, emission collection: $665 \mathrm{~nm}$ long pass. Each image (optical sections passed through the nuclei) is the average of 4 successive image acquisition.

\section{Intracellular Oxygen measurement in suspended HUVEC.}

Sub-confluent adhering HUVEC were washed twice with PSS and trypsinized. Trypsinization was stopped by addition of PSS containing 50\% human serum. Cells were then centrifuged $5 \mathrm{~min}$ at $200 \times g$ and resuspended in $6 \mathrm{ml}$ PSS with $0.45 \mathrm{mg}_{\mathrm{m}} \mathrm{ml}^{-1}$ pluronic F-127, $5 \mathrm{mg} \cdot \mathrm{ml}^{-1}$ BSA added. Sixty microliters of a $10 \mathrm{mM}$ PdTCPPNa 4 solution were added to a $6 \mathrm{ml}$ cell suspension (final concentrations: $100 \mu \mathrm{M}$ PdTCPPNa 4 ) before a $60 \mathrm{~min}$ incubation at $37^{\circ} \mathrm{C}, 5 \% \mathrm{CO}_{2}$, humid atmosphere, in the dark. The cells were then washed of the extracellular fluorescent probe by four centrifugation cycles $(5 \mathrm{~min}, 200 \times g)$ and pellet resuspension in $6 \mathrm{ml}$ PSS containing $4 \mathrm{mM}$ octanoate $\quad\left(\approx 10^{6} \mathrm{cells}^{\mathrm{s}} \cdot \mathrm{ml}^{-1}\right)$.

eNOS is activated using $0.1,1$ and $10 \mu \mathrm{M}$ acetylcholine (Ach) (18) or inhibited using $10 \mu \mathrm{M}$ $\mathrm{N}-\omega$-nitro-L-arginine methyl ester (L-NAME), an analogue of the precursor L-Arginine which cannot

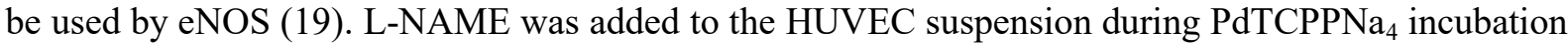
(60min). The cell suspension was then washed out of the probe and L-NAME by centrifugation and resuspension in PSS before measurement.

In addition, to evaluate the interaction between $\mathrm{PdTCPPNa}_{4}$ and the chemicals used in this study, the chemicals were added to a $10 \mu \mathrm{M}$ PdTCPPNa ${ }_{4}$ solution (without cells) during the phosphorescence 
emission acquisition.

Two different parameters were measured, depending on the experimental condition: phosphorescence intensity (I) or phosphorescence decay $(\tau)$. $\tau$ and I were obtained using a pulsed water cooled continuous wave ArGa laser excitation $(514 \mathrm{~nm})$ and a continuous laser beam $(514 \mathrm{~nm})$, respectively, and the $90^{\circ}$ phosphorescence emission was detected at 710nm with a AsGa photomultiplier.

Probe and Chemicals. Chemicals were obtained from Sigma except potassium cyanide $(\mathrm{KCN})$ and 2,4 dinitrophenol (DNP) provided by Merck. PdTCPPNa ${ }_{4}$ is prepared as reported above.

Computer Analysis. Exponential decay curve analysis was performed by using the Origin 5.0 Microcal Origin Software. For suspended HUVEC intracellular origin measurements, phosphorescence acquisition was performed by using software written by the authors. The averaging of 100 successive exponential decays was used to measure $\tau$. 


\section{RESULTS}

\section{Optimization of experimental conditions}

Validation of the loading protocol

Figure 1B illustrates that PdTCPPNa 4 enters human umbilical venous endothelial cells (HUVEC), as seen from the fluorescence confocal microscopy signal (optical slices passing through the nuclei). The weakness of the intracellular fluorescence is expected because of the low quantum yield of this probe. The strong photobleaching due to the repeated laser scanning of the whole microscopic field did not allow further sequential acquisition of images using the confocal microscopy technique. Consequently, all further experiments were carried out on HUVEC suspensions.

Optimal concentrations of $K C N$ and 2.4-dinitrophenol for modulation of mitochondrial respiration in endothelial cells

On HUVEC suspension, using the oxygraphy technique, uncoupling by $100 \mu \mathrm{M}$ DNP stimulates the respiratory rate up to 2 -fold within a few seconds, and $1 \mathrm{mM} \mathrm{KCN}$ is an optimal concentration which induces almost an immediate 10 -fold inhibition of respiration. However, $1 \mathrm{mM} \mathrm{KCN}$ also induces a rapid morphological deterioration of cells observed in confocal microscopy. Since $100 \mu \mathrm{M}$ KCN does not induce cell morphological changes while still inhibiting the respiratory rate by 2 -fold (data not shown), $100 \mu \mathrm{M} \mathrm{KCN}$ and $100 \mu \mathrm{M}$ DNP have been used as respiration modulators in the following experiments.

\section{Lack of interaction between the PdTCPPNa ${ }_{4}$ and the chemicals added}

It has been verified that acetylcholine and L-NAME do not directly affect the optical properties of PdTCPPNa $_{4}$ by direct molecular interaction in an acellular physiological solution (Fig. 2A and 2B). Besides, we have observed that the average values of the measured probe phosphorescence decays are different in physiological solution and in cells (about $6 \mu \mathrm{sec}$ and $90 \mu \mathrm{sec}$, respectively). This can result from the different molecular environment around the probe. In accordance with the literature (12), we have observed, using bovine serum albumin (BSA) addition to PdTCPPNa 4 solutions, that the presence of protein induces an increase in the probe luminescence. The same phenomenon likely 
occurs when the probe is loaded in the protein-rich cytoplasm of the cell.

\section{Experimental results}

Intracellular $\mathrm{PO}_{2}$ variations during modification of extracellular oxygen tension

Argon bubbling (50 min) of a suspended HUVEC loaded with PdTCPPNa $\mathrm{Na}_{4}$ was used to deplete the extracellular medium of solubilized $\mathrm{O}_{2}$, and phosphorescence intensity was recorded. PdTCPPNa phosphorescence intensity increased by 7 fold, plateauing after $25 \mathrm{~min}$ (Fig. 3 ). This indicates that PdTCPPNa 4 strongly responds to the intracellular $\mathrm{PO}_{2}$ decrease induced by extracellular decrease in oxygen tension.

\section{Mitochondrial respiration and $\mathrm{PO}_{2}$ variations}

Under these conditions, the measurement of phosphorescence decay $(\tau)$ avoids the problem of working with the very weak signal of PdTCPPNa $a_{4}$. As shown in figure 4, the addition of $100 \mu \mathrm{M}$ DNP or $100 \mu \mathrm{M}$ KCN does not modify the initial value of the phosphorescence decay $(\tau)$ over $30 \mathrm{~min}$ in PdTCPPNa $a_{4}$-loaded HUVEC, suggesting that mitochondrial respiration does not significantly influence $\mathrm{PO}_{2}$.

Non-respiratory oxygen consumption by eNOS and variations of $\mathrm{PO}_{2}$

Addition of $0.1,1$ and $10 \mu \mathrm{M}$ acetylcholine to HUVEC induce transient and dose-dependent increases in $\tau$ (Fig. 5A, Fig. 6A, 6B, 6C), generally occurring after $2-5$ minutes (up to $10 \mathrm{~min}$ in a few experiments), whereas no increase in $\tau$ is observed in the corresponding control experiments (Fig. 5B). These results suggest a significant reduction of the intracellular $\mathrm{PO}_{2}$ under acetylcholine stimulation. The average percentages of increase in amplitude of the phosphorescence decay peaks, as compared to baseline, are in the range of $4.2 \%(0.1 \mu \mathrm{M}$ Ach), $23 \%(1 \mu \mathrm{M}$ Ach) and $81.6 \%(10 \mu \mathrm{M}$ Ach) (Fig. $6 \mathrm{D})$. A statistical analysis using a one-way ANOVA showed that the average percentages of increase in the amplitude of the phosphorescence decay peaks are significantly dependent upon the acetylcholine dose $(\mathrm{P}<0.05)$ 
Figure 5C shows that there is no increase in $\tau$ in response to $1 \mu \mathrm{M}$ acetylcholine immediately after incubation with L-NAME. This tracing is comparable to the control (Fig. 5B). Nevertheless, 2 hours after the end of L-NAME incubation, after eNOS activity resumed, the acetylcholine-induced $\tau$ elevation -therefore $\mathrm{PO}_{2}$ decrease- is restored (Fig. 5D). The fact that no detectable modification of luminescence, following Ach addition on L-NAME-treated HUVEC, indicates a causal relationship between $\mathrm{O}_{2}$ consumption related to eNOS activation and the transient increase in $\tau$. Moreover, the literature mentioned that a few porphyrins are sensitive to NO (20) or can be used as NO probe (21). Consequently, 10 and $100 \mathrm{nmol} \mathrm{NO}$ (final concentrations: $3 \mu \mathrm{M}$ and $30 \mu \mathrm{M}$, respectively) have successively been added to a PdTCPPNa ${ }_{4}$ solution $(10 \mu \mathrm{M})$ in PSS, in order to verify that NO does not modify the value of $\tau$ corresponding to our probe (Fig. $2 \mathrm{C}$ ). Therefore, these results depict actual $\mathrm{PO}_{2}$ modifications rather than NO level detection. 


\section{DISCUSSION}

The present in vitro study validate a novel technique for measuring intracellular $\mathrm{PO}_{2}$ variations in acellular solutions as well as in living cells. Although, values of basal phosphorescent decay in acellular solutions (Fig. 2) and in living cells (Figs. 4 and 5) are different because the local environment surrounding the probe in the cell is likely to affect its response to $\mathrm{PO}_{2}$ variations. $\mathrm{PdTCPPNa}_{4}$ loaded into human umbilical venous endothelial cells (HUVEC) exhibits spectral properties similar to the well characterized phosphorescent oxygen probe $\mathrm{Pd}$ meso-tetra (4-carboxyphenyl) porphyrin (12). Moreover $\mathrm{PdTCPPNa}_{4}$ could be used for the measurement of intracellular oxygen tension $\left(\mathrm{PO}_{2}\right)$ variations in living HUVEC, as shown by the intracellular response to extracellular $\mathrm{PO}_{2}$ decrease induced by argon bubbling (Fig. 3). The original loading protocol used in this study, in contrast with microinjection techniques which allows measurements in a few cells at a given time (11), enables the study of intracellular $\mathrm{PO}_{2}$ in a population of millions of cells. Furthermore, microscopy studies do not show any morphological cell damage due to PdTCPPNa 4 loaded in HUVEC, even under focused light (Fig. 1B). In addition, the fact that low intracellular concentrations of PdTCPPNa 4 were used is likely to keep the effect of any reactive $\mathrm{O}_{2}$ species produced, due to energy transfer from the porphyrin probe in its excited state to molecular oxygen, at a very low level.

Extracellular oxygen transport towards the inside of the cell occurs by diffusion according to the gradient of concentration and tends to maintain a constant $\mathrm{PO}_{2}$. Using data from the literature $(3,4)$, theoretical maximum oxygen flow entering the cell by diffusion can be estimated in the range of $3 \times 10^{-15} \mathrm{~mol} \mathrm{O}_{2} \cdot \mathrm{sec}^{-1} \cdot \mathrm{cell}^{-1}$ and oxygen uptake measured by oxygraphy in HUVEC $\left(37^{\circ} \mathrm{C}\right)$ has been found at a basal level, about 75 times lower: $4 \times 10^{-17} \mathrm{~mol} \mathrm{O}_{2} \cdot \mathrm{sec}^{-1} \cdot \mathrm{cell}^{-1}(8)$. Therefore, physiological modulations of mitochondrial respiration, which usually vary by a factor 2-4 times (8), should have no impact on intracellular $\mathrm{PO}_{2}$, because $\mathrm{O}_{2}$ diffusion flow allows a $\mathrm{O}_{2}$ influx 20-50 fold higher. Thus, it is not surprising that, in these conditions, modulation of mitochondrial respiration using $100 \mu \mathrm{M}$ $\mathrm{KCN}$ or $100 \mu \mathrm{M} \mathrm{DNP}$, which respectively inhibits and stimulates respiratory function by 2 -fold, does not measurably modify $\mathrm{PO}_{2}$ (Fig. 4).

Besides, oxygen consumption independent from respiration and resulting from activation of endothelial nitric oxide synthase (eNOS) has been evaluated. The use of a NO sensitive 
microelectrode previously allowed to calculate NO concentration, at a distance of $50 \mu \mathrm{m}$ from the surface of rat aorta endothelial cell, in the range of $6.2 \times 10^{-16} \mathrm{~mol} \mathrm{NO} \cdot \mathrm{sec}^{-1} \cdot \mathrm{cell}^{-1}(22)$. Therefore, since NO synthesis has a stoichiometry of $1 / 1$ with regard to consumed $\mathrm{O}_{2}$, the basal production of $\mathrm{NO}$ by eNOS in rat aorta single endothelial cell requires the consumption of about $6.2 \times 10^{-16} \mathrm{~mol}$ $\mathrm{O}_{2} \cdot \sec ^{-1} \cdot$ cell $^{-1}$. Moreover, eNOS has been shown to be activated by endothelial cell stimulation with acetylcholine (Ach), leading to activation of NO release (23). In the endothelium from rabbit aorta, Ach increases NO extracellular level -therefore production- by $\approx 10$ times (23) and probably more if intracellular NO degradation is taken into account. Therefore, the corresponding quantity of $\mathrm{O}_{2}$ transiently consumed by Ach-stimulated eNOS can be evaluated in the range of 10 times the basal consumption, i.e. $6.2 \times 10^{-15} \mathrm{~mol} \mathrm{O} \cdot \mathrm{sec}^{-1} \cdot \mathrm{cell}^{-1}$. This value is about 2 fold higher than the maximum rate of $\mathrm{O}_{2}$ diffusion through the cell membrane. Consequently, eNOS activation is a physiological mechanism which can induce a much stronger decrease in intracellular $\mathrm{PO}_{2}$ than modulation of respiration. Our experiments corroborate this calculation, since $0.1-10 \mu \mathrm{M}$ acetylcholine induce transient and dose-dependent increases in PdTCPPNa ${ }_{4}$-loaded cell phosphorescence decay, indicating a corresponding $\mathrm{PO}_{2}$ reduction (Fig. 5A and Fig. 6). On the contrary, no change in porphyrin phosphorescence was observed when cell respiration was increased or decreased by the use of DNP or $\mathrm{KCN}$ (Fig. 4). Also, as expected, no $\mathrm{PO}_{2}$ variation is detected in response to acetylcholine when eNOS is blocked by L-NAME (Fig. $5 \mathrm{C}$ and D).

The present results suggest that other oxygen-related mechanisms of the cell physiology can now be further investigated using cell loading with PdTCPPNa 4 . 


\section{REFERENCES}

1. Meyer, P. (1983). Physiologie humaine, pp. 1088-1099, Flammarion Medecine-Sciences, Paris.

2. Nathan, C., and Xie, Q. W. (1994). Nitric oxide synthases: roles, tolls, and controls. Cell 78, 915-8.

3. Clark, A., Jr., Clark, P. A., Connett, R. J., Gayeski, T. E., and C. R. Honig, C. R. (1987). How large is the drop in PO2 between cytosol and mitochondrion? Am. J. Physiol. 252, C583-7.

4. Hogan, M. C., Mathieu-Costello, O., Poole, D.C., and Wagner, P. D. (1994). Oxygen transport to tissue XVI. New York: Plemium Press, p. 22-23.

5. Kekonen, E. M., Jauhonen, V. P., and Hassinen, I. E. (1987). Oxygen and substrate dependence of hepatic cellular respiration: sinusoidal oxygen gradient and effects of ethanol in isolated perfused liver and hepatocytes. J. Cell Physiol. 133, 119-26.

6. Whalen, W. J. (1971). Intracellular PO2 in heart and skeletal muscle. Physiologist 14, 69-82.

7. Whalen, W. J., Riley, J., and Nair, P. (1967). A microelectrode for measuring intracellular PO2. J. Appl. Physiol. 23, 798-801.

8. Steinlechner-Maran, R., Eberl, T., Kunc, M., Margreiter, R., and Gnaiger, E. (1996). Oxygen dependence of respiration in coupled and uncoupled endothelial cells. Am. J. Physiol. 271, C2053-61.

9. Buerk, D. G., Tsai, A. G., Intaglietta, M., and Johnson, P. C. (1998). Comparing tissue PO2 measurements by recessed microelectrode and phosphorescence quenching. Adv. Exp. Med. Biol. 454, 367-74.

10. Richmond, K. N., Shonat, R. D., Lynch, R. M., and Johnson, P. C. (1999). Critical PO(2) of skeletal muscle in vivo. Am. J. Physiol. 277, H1831-40.

11. Hogan, M. C. (1999). Phosphorescence quenching method for measurement of intracellular PO2 in isolated skeletal muscle fibers. J. Appl. Physiol. 86, 720-4.

12. Lo, L. W., Koch, C. J., and Wilson, D. F. (1996). Calibration of oxygen-dependent quenching of the phosphorescence of Pd-meso-tetra (4-carboxyphenyl) porphyrin: a phosphor with general application for measuring oxygen concentration in biological systems. Anal. Biochem. 236, 153-60.

13. Vanderkooi, J. M., Maniara, G., Green, T. J., and Wilson, D. F. (1987). An optical method for measurement of dioxygen concentration based upon quenching of phosphorescence. J. Biol. Chem. 262, 5476-82.

14. Wilson, D. F., and Vinogradov, S. A. (1994). Recent advances in oxygen measurements using 
phosphorescence quenching. Adv. Exp. Med. Biol. 361, 61-6.

15. Buderus, S., Siegmund, B., Spahr, R., Krutzfeldt, A., and Piper, H. M. (1989). Resistance of endothelial cells to anoxia-reoxygenation in isolated guinea pig hearts. Am. J. Physiol. 257, H488-93. 16. Jaffe, E. A., Nachman, R. L., Becker, C. G., and Minick, C. R. (1973). Culture of human endothelial cells derived from umbilical veins. Identification by morphologic and immunologic criteria. J. Clin. Invest. 52, 2745-56.

17. Faury, G., Usson, Y., Robert-Nicoud, M., Robert, L. and Verdetti, J. (1998). Nuclear and cytoplasmic free calcium level changes induced by elastin peptides in human endothelial cells. Proc. Natl. Acad. Sci. USA. 95, 2967-2972.

18. Lüscher, T.F., and Vanhoutte, P. M. (1990). The endothelium: modulator of cardiovascular function. Boca Raton: CRC Press.

19. Rees, D. D., Palmer, R. M. J., Schulz, R., Hodson, H. F., and Moncada, S. (1990). Characterization of three inhibitors of endothelial nitric oxide synthase in vitro and in vivo. Br. J. Pharmacol. 101, $746-752$.

20. Pawlowski, M., and Wilson, D. F. (1994). Imaging oxygen pressure in tissue in vivo by phosphorescence decay. Adv. Exp. Med. Biol. 361, 83-91.

21. Clark, H. A., Barker, S. L. R., Brasuel, M., Miller, M. T., Monson, E., Parus, S., Shi, Z. Y., Song, A., Thorsrud, B., Kopelman, R., Ade, A., Meixner, W., Athey, B., Hoyer, M., Hill, D., Lightle, R., and Phylbert, M.A. (1998). Subcellular optochemical nanobiosensors: probbes encapsulated by biologically localised embedding (PEBBLEs). Sensors and Actuators. B 51, 12-16.

22. Brovkovych, V., Dobrucki, L. W., Brovkovych, S., Dobrucki, I., Do Nascimento, C.A., Burewicz, A., and Malinski., T. (1999). Nitric oxide release from normal and dysfunctional endothelium. $J$. Physiol. Pharmacol. 50, 575-86.

23. Christie, M. I., Griffith, T. M., and Lewis, M. J. (1989). A comparison of basal and agonist-stimulated release of endothelium-derived relaxing factor from different arteries. $B r . J$. Pharmacol. 98, 397-406. 
FIGURE LEGENDS

Figure 1. Emission spectrum of the water soluble PdTCPPNa $\mathrm{P}_{4}$ illuminated by a $514 \mathrm{~nm}$ laser beam (A.). Adherent HUVEC loaded with PdTCPPNa 4 observed by confocal laser scanning microscopy in differential interferential contrast (left) and fluorescence (right) (B.). The images presented are representative of two experiments.

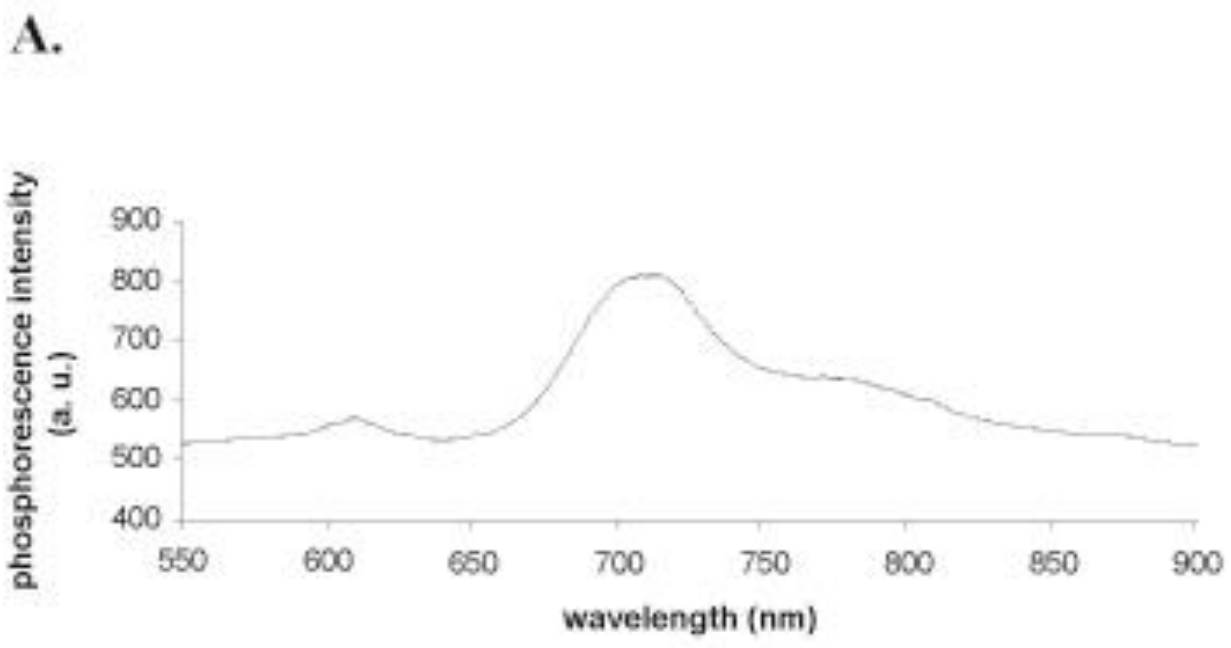

B.

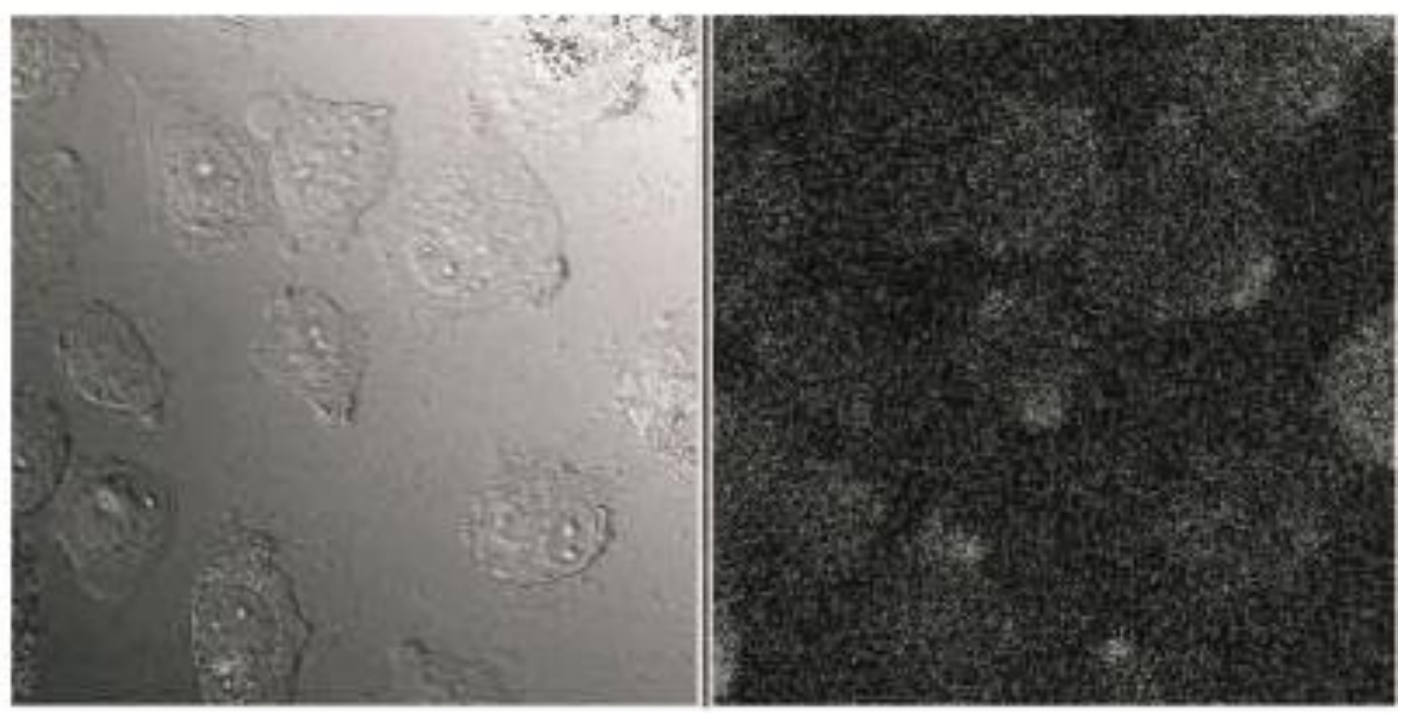

$175 \mu \mathrm{m}$ 
Figure 2. Absence of interaction of NO, Ach and L-NAME on the luminescence properties of $\mathrm{PdTCPPNa}_{4}(10 \mu \mathrm{M})$ in PSS. (A.) Effects of $1 \mu \mathrm{M}$ acetylcholine or $10 \mu \mathrm{M}$ L-NAME on the $10 \mu \mathrm{M}$ porphyrin solution. (B.) Effects of $1 \mu \mathrm{M}$ acetylcholine and $10 \mu \mathrm{M}$ L-NAME on the $10 \mu \mathrm{M}$ porphyrin solution and corresponding control tracing. (C.) Sensitivity of the porphyrin probe $(10 \mu \mathrm{M})$ to successive additions of 10 and $100 \mathrm{nmol}$ NO. Arrows: product addition. A representative tracing is shown ( $\mathrm{n}=2$ in each case).
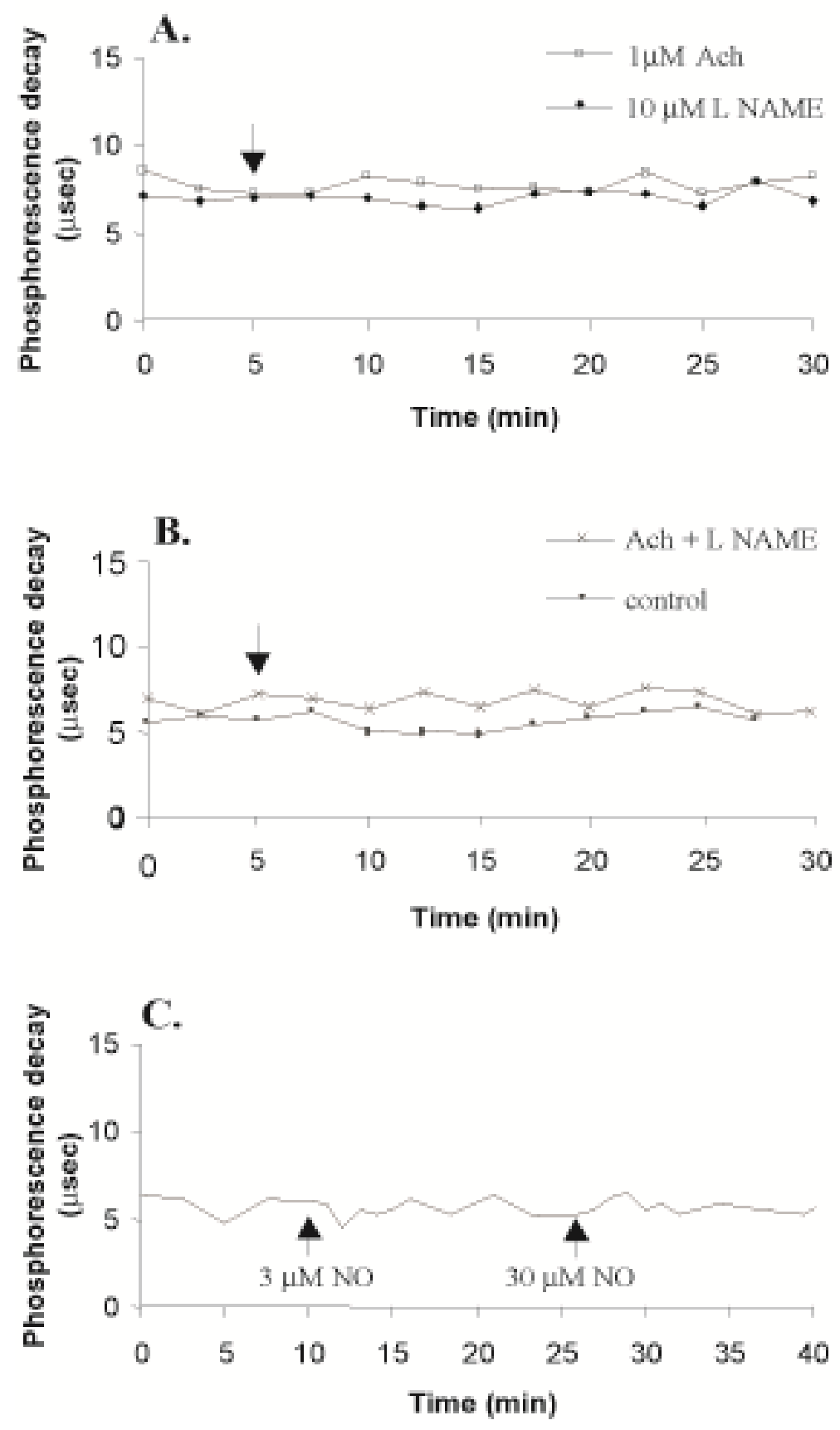
Figure 3. Effect of argon bubbling on the phosphorescence intensity of PdTCPPNa ${ }_{4}$-loaded HUVEC suspension. The argon bubbling starts at time $0 \mathrm{~min}$.

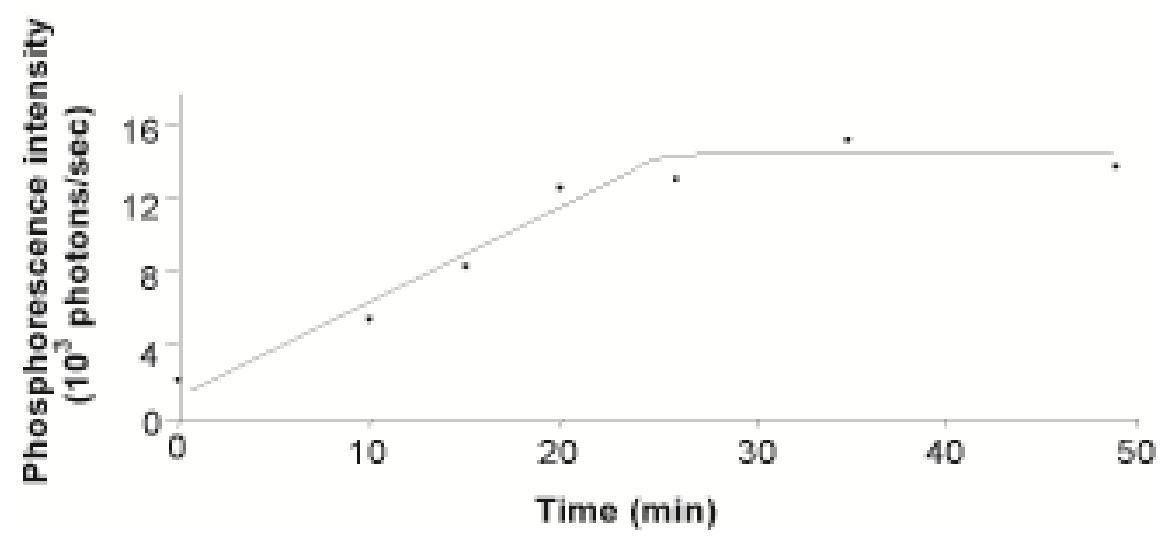


Figure 4. Effect of $100 \mu \mathrm{M}$ DNP (A.) and $100 \mu \mathrm{M} \mathrm{KCN}$ (B.) on the phosphorescence decay of $100 \mu \mathrm{M}$ PdTCPPNa 4 -loaded HUVEC suspension. A control tracing is shown in C. A representative tracing is shown ( $\mathrm{n}=2$ in each case).

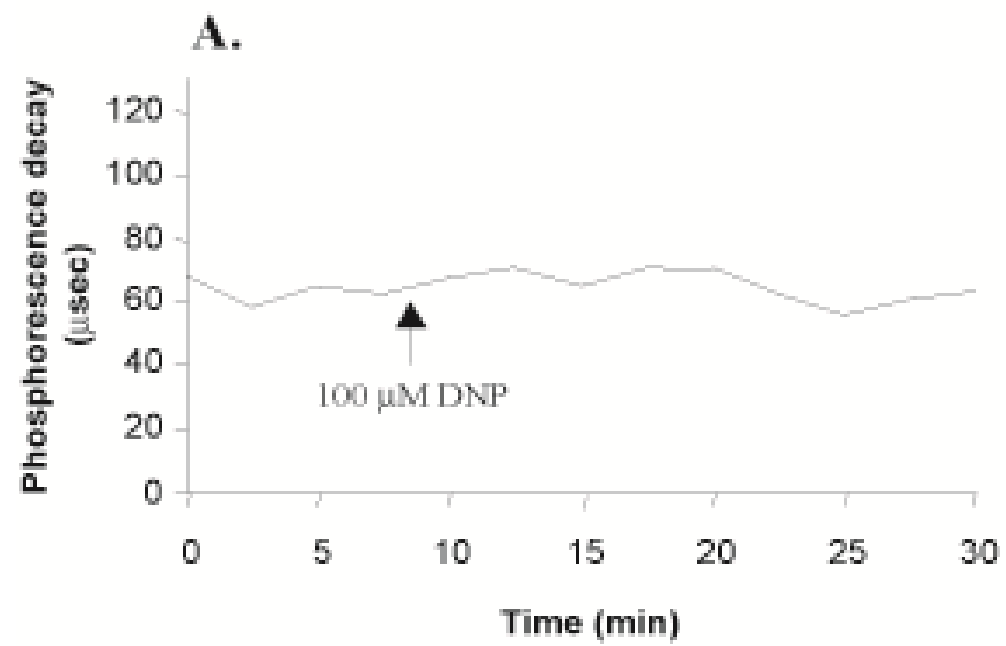

B.

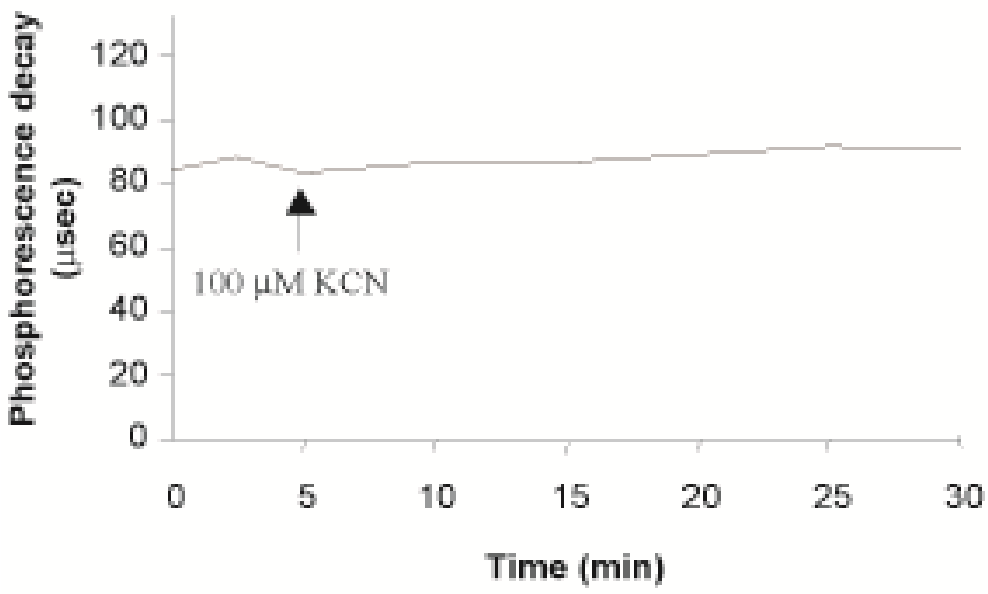

C.

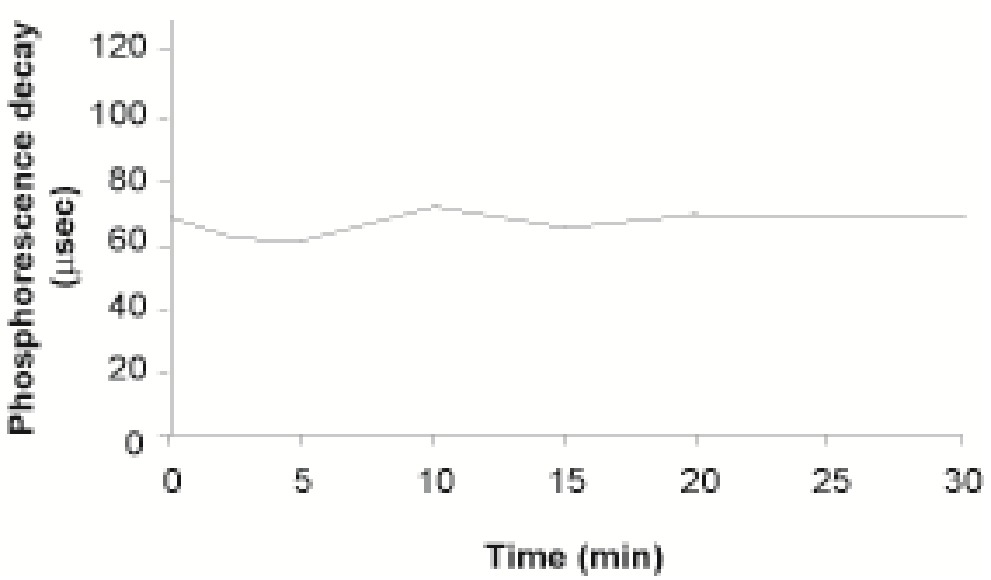


Figure 5. $1 \mu \mathrm{M}$ acetylcholine (Ach) induces a transient lengthening of phosphorescence decay $(\tau)$ on $100 \mu \mathrm{M}$ PdTCPPNa 4 -loaded HUVEC (A.). Control tracing (B.). Effect, on $100 \mu \mathrm{M}$ PdTCPPNa 4 -loaded HUVEC, of $1 \mu \mathrm{M}$ Ach immediately after incubation with $10 \mu \mathrm{M}$ L-NAME (C.) and 2 hours after the end of L-NAME incubation (D.). A representative tracing is shown in each case (A: $n=3 ; B, C, D$ : $\mathrm{n}=2)$.

A.

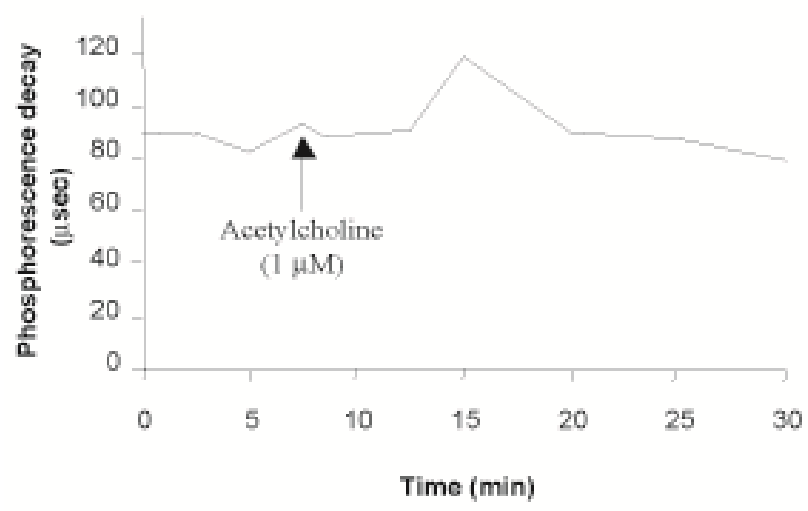

C.

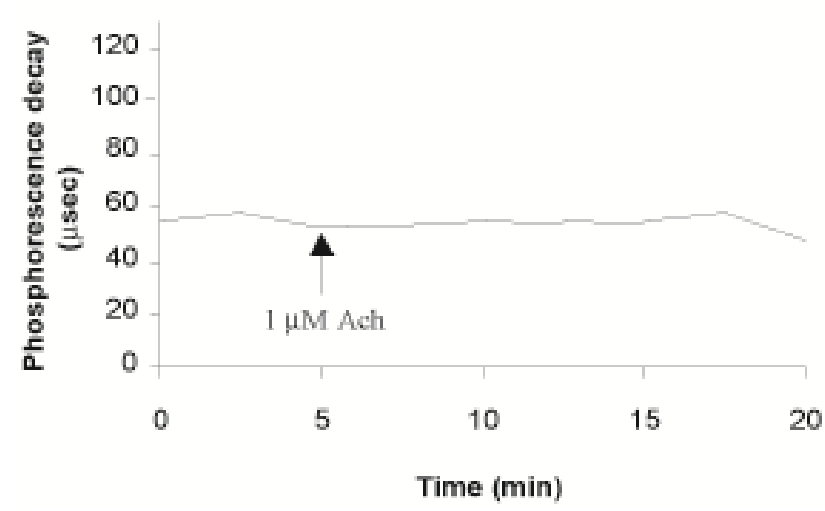

B.

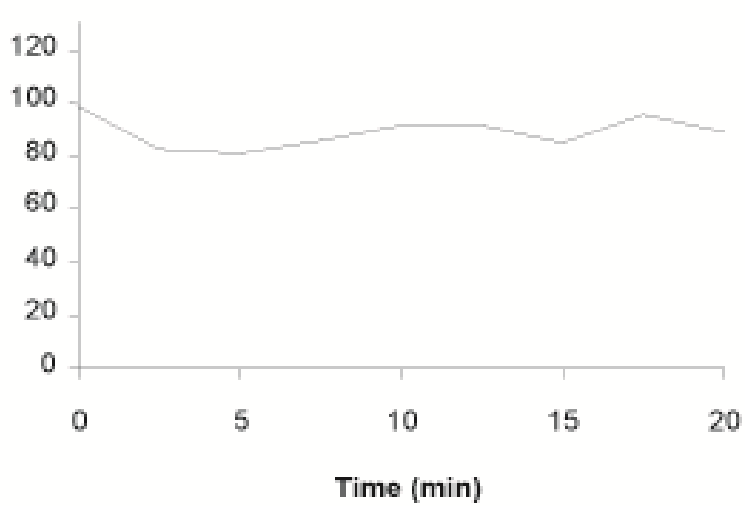

D.

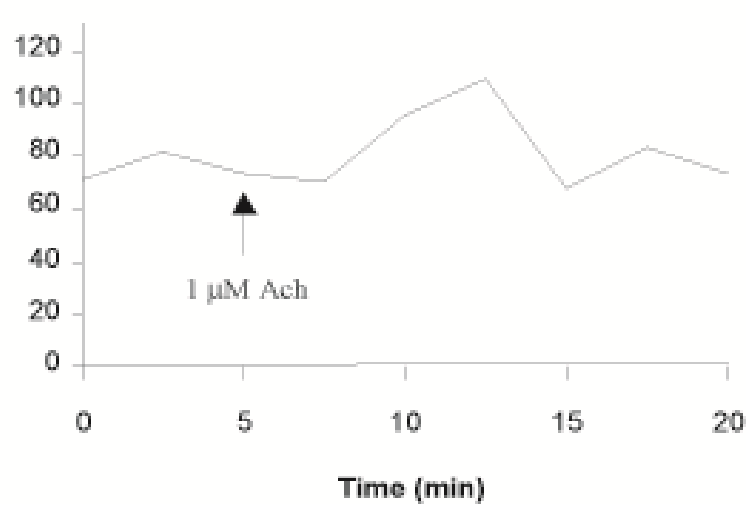


Figure 6. Dose-effect of acetylcholine (Ach) on the phosphorescence decay $(\tau)$ of $100 \mu \mathrm{M}$ PdTCPPNa 4 -loaded HUVEC. The amplitude of the phosphorescence decay peak induced by Ach addition increases with Ach concentration: $0.1 \mu \mathrm{M}$ (A), $1 \mu \mathrm{M}$ (B) and $10 \mu \mathrm{M}$ (C). A representative tracing is shown in each case (A: $n=5 ; B$ and $C: n=4)$. The arrows indicate the time of Ach addition (A, B and C). The average percentages of increase in amplitude of the phosphorescence decay peaks induced by Ach, as compared to baseline, were calculated for each Ach dose using the results from all experiments, and represented in D.
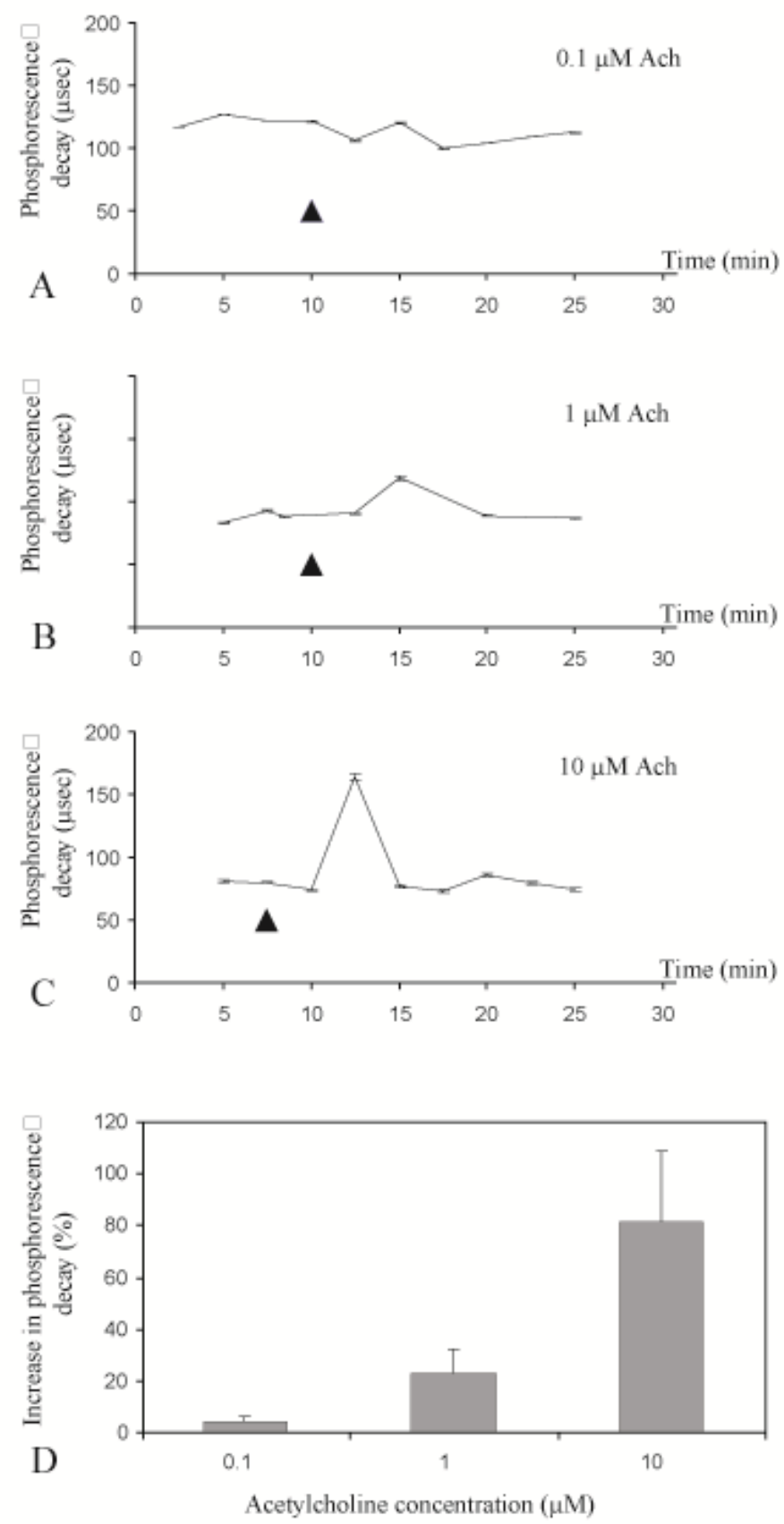